\title{
The regulation of the air: a hypothesis
}

\author{
E. G. Nisbet $^{1}$, C. M. R. Fowler ${ }^{1}$, and R. E. R. Nisbet ${ }^{2}$ \\ ${ }^{1}$ Department of Earth Sciences, Royal Holloway, University of London, Egham, Surrey, TW20 0EX, UK \\ ${ }^{2}$ Sansom Institute, University of South Australia, North Terrace, Adelaide, SA 5000, Australia \\ Correspondence to: E. G. Nisbet (e.nisbet@es.rhul.ac.uk)
}

Received: 6 September 2011 - Published in Solid Earth Discuss.: 14 September 2011

Revised: 14 February 2012 - Accepted: 15 February 2012 - Published: 12 March 2012

\begin{abstract}
We propose the hypothesis that natural selection, acting on the specificity or preference for $\mathrm{CO}_{2}$ over $\mathrm{O}_{2}$ of the enzyme rubisco (ribulose-1,5-bisphosphate carboxylase/oxygenase), has controlled the $\mathrm{CO}_{2}: \mathrm{O}_{2}$ ratio of the atmosphere since the evolution of photosynthesis and has also sustained the Earth's greenhouse-set surface temperature. Rubisco works in partnership with the nitrogen-fixing enzyme nitrogenase to control atmospheric pressure. Together, these two enzymes control global surface temperature and indirectly the $\mathrm{pH}$ and oxygenation of the ocean. Thus, the co-evolution of these two enzymes may have produced clement conditions on the Earth's surface, allowing life to be sustained.
\end{abstract}

\section{Introduction}

The past is the sum of the presents. Modern air is a biological construction (Fig. 1). Air pressure is largely (78\%) determined by nitrogen. Nitrogen is a product of the biological nitrogen cycle, with $\mathrm{N}_{2}$ made by denitrification and anammox reactions. It is fixed by nitrifying bacteria, with only small inorganic $\mathrm{N}$ fluxes via volcanic gases and lightning. The combined inputs of anammox planctomycete bacteria and denitrifying bacteria have created a global reservoir of $\mathrm{N}_{2}$ that gives bulk to the air and the weather, helps sustain the greenhouse by pressure broadening, and provides a globally accessible $\mathrm{N}_{2}$ supply for nitrogen fixation.

The nitrogen cycle is closely linked to the carbon cycle (Falkowski, 1997). Nearly $21 \%$ of the air is $\mathrm{O}_{2}$, which is the product of the extraction of carbon from $\mathrm{CO}_{2}$ in the air by photosynthesis. $\mathrm{CO}_{2}$ is now about 390 parts per million, but $\sim 280-300 \mathrm{ppm}$ in the pre-industrial Holocene, and as low as $190 \mathrm{ppm}$ in glacial maxima. Dark respiration in all living organisms, in which cells take up $\mathrm{O}_{2}$ and release $\mathrm{CO}_{2}$, is the inverse side of the photosynthetic coin. On a planetary scale, the fluxes of photosynthesis and respiration are broadly reciprocal (e.g. Keeling and Shertz, 1992). Without photosynthetic oxygen, in a biosphere dominated by anaerobic metabolic processes such as fermentation, only limited cellular respiration could occur. Methane's mixing ratio (concentration) in the air is now $\sim 1.8 \mathrm{ppm}$, and was $\sim .65 \mathrm{ppm}$ in the Holocene, $\sim .35 \mathrm{ppm}$ in glacial maxima. Apart from thermogenic methane made by geological heating of organic matter, the bulk of the production of methane is by methanogenesis. This is carried out by archaebacteria using substrates such as acetate or hydrogen. Methanogenesis is largely dependent on the degradation of organic compounds and thus is in essence the recycling of photosynthetic productivity. Even the biota living around hydrothermal vents on mid-ocean ridge volcanoes depend on the supply of sulphate from the oxygen-rich surface ocean (although methanogenesis can also occur using $\mathrm{H}_{2}$ produced abiotically by the reaction between water and hot newly-erupted basalt).

\section{Carbon transfers}

The transfer of atmospheric $\mathrm{CO}_{2}$ from the air to the interior of photosynthetic cells is expedited by a variety of mechanisms, including the $\mathrm{CO}_{2}$ concentrating mechanism (Badger et al., 2006). The delivery of $\mathrm{CO}_{2}$ to photosynthetic organelles is not a trivial accomplishment. Despite this, entry of carbon into the cell is generally efficient, with little fractionation between ${ }^{12} \mathrm{C}$ and ${ }^{13} \mathrm{C}$. This high isotopic efficiency implies a high yield and thus nearly all the carbon accessed from the external environment is transferred into the cell.

Once inside the cell the rubisco enzyme, the most abundant protein on Earth, catalyses the fixation of $\mathrm{CO}_{2}$. There are various forms of rubisco. Rubisco I, the most abundant, facilitates oxygenic photosynthesis. As both carboxylase and 


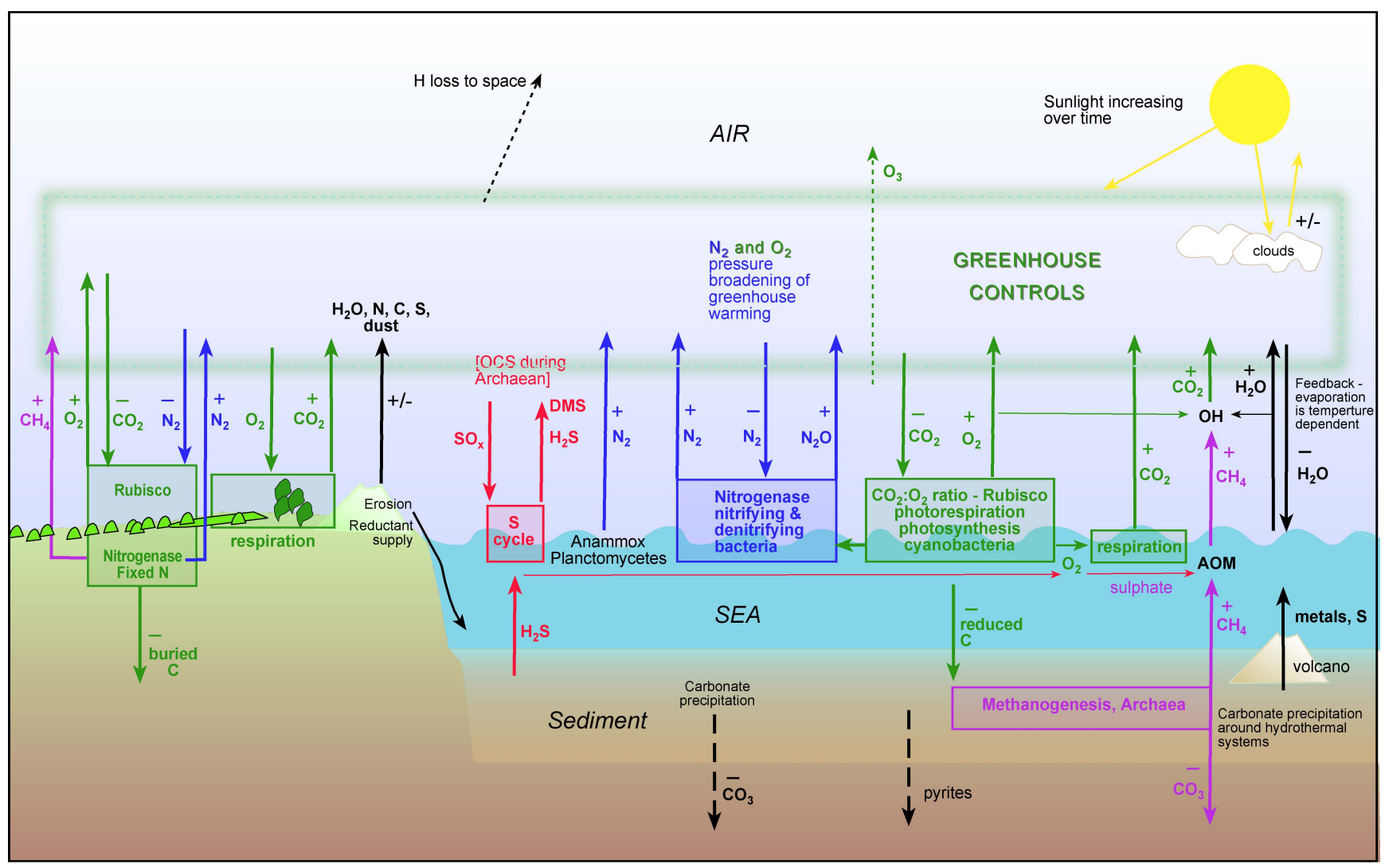

Fig. 1. Biological controls on atmospheric composition, pressure and temperature. Positive and negative temperature forcing is shown by + and - symbols. Green shading on land represents photosynthetic life. Abbreviations: AOM - anaerobic methane oxidation; AIR - natural mix, now mainly $\mathrm{N}_{2}$ and $\mathrm{O}_{2}$, but previously with $\mathrm{CO}_{2}$ and $\mathrm{CH}_{4}$; other letters are chemical species.

oxygenase, rubisco operates with either $\mathrm{CO}_{2}$ or $\mathrm{O}_{2}$ as substrate, either selecting $\mathrm{CO}_{2}$ from the atmosphere to capture $\mathrm{C}$ into organic life or, in its oxidase function, capturing $\mathrm{O}_{2}$ to initiate the photorespiration pathway. The specificity of the enzyme is the measure of its selection of $\mathrm{CO}_{2}$ over $\mathrm{O}_{2}$ for uptake in preference to emission.

As the rubisco I enzyme is highly selective, and $\mathrm{CO}_{2}$ is abundant, only a part of the accessible $\mathrm{CO}_{2}$ is chosen for incorporation into organic product. Thus, rubisco-catalysed carbon fixation causes strong isotopic fractionation. Oxygenic photosynthetic organisms, including plants, eukaryotic algae and cyanobacteria, mimic the response of a virtual $\mathrm{Ru}-$ bisCO that reacts to the variations of external $\mathrm{CO}_{2}$ and $\mathrm{O}_{2}$ concentrations. This allows the definition (Andre, 2011a) of a Plant Specificity, $S p$ (with dimensions of $\%$ per ppm), where, if $\mathbf{v}_{\mathrm{c}}$ is the rate of the oxygenase and $\mathbf{v}_{\mathrm{c}}$ of the carboxylase process, $\mathrm{C}$ is the $\mathrm{CO}_{2}$ in the external atmosphere, and $\mathrm{O}$ is the $\mathrm{O}_{2}$ in the external atmosphere, then $\mathbf{v}_{\mathrm{c}} / \mathbf{v}_{\mathrm{o}}=S p$ $\mathrm{C} / \mathrm{O}$ in low to moderate irradiance (Andre, 2011a).

Rubisco I may have evolved in cyanobacteria nearly $3 \mathrm{Ga}$ ago (Nisbet et al., 2007), yet rubisco's "specificity" (its preference for $\mathrm{CO}_{2}$ over $\mathrm{O}_{2}$ ) remains paradoxically restricted. In contrast with other enzymes, rubisco seems inefficient, with a sluggish reaction rate (Tcherkez et al., 2006). However, rubisco's "inefficiency" may be deceptive. On a molecular level, analysis of the kinetics and isotopic fractionation of rubisco I in oxygenic photosynthetic organisms (Tcherkez et al., 2006) suggests that evolution has led to a near-perfect compromise between catalytic turnover and $\mathrm{CO}_{2}: \mathrm{O}_{2}$ specificity (Gutteridge and Pierce, 2006). Organisms that that are adapted to higher $\mathrm{CO}_{2}: \mathrm{O}_{2}$ ratios contain rubisco with higher catalytic rates and lower specificity. In contrast, a rubisco enzyme with a higher specificity (i.e. more able to select for $\mathrm{CO}_{2}$ at low $\mathrm{CO}_{2}: \mathrm{O}_{2}$ ratios) will operate only at lower temperatures and lower rates (Tcherkez et al., 2006), and will thus suit organisms adapted to a different range of habitats on the climatically varied planet. In each photosynthetic species, the rubisco enzymes may be nearly optimally fitted to their specific tasks, each exquisitely tuned to the local environment (Tcherkez et al., 2006; Gutteridge and Pierce, 2006) under a globally mixed atmosphere.

On a microscopic scale (e.g. chloroplasts), the $\mathrm{CO}_{2}$ "compensation point", $\Gamma_{\mathrm{CO}_{2}}$ (Farquhar et al., 1980), defines the equilibrium between $\mathrm{CO}_{2}$ uptake by photosynthesis and release by photorespiration. In plants (e.g. in soil in a bell jar: Tolbert et al., 1995), the $\mathrm{CO}_{2}$ compensation point is the 
$\mathrm{CO}_{2}$ concentration at which net $\mathrm{CO}_{2}$ fixation is zero. On the global scale (Berry et al., 1994), this is the $\mathrm{CO}_{2}$ level for which the total $\mathrm{CO}_{2}$ evolution (dark respiration) by all living organisms is equilibrated by carboxylation by plants. As carbon dioxide re-supply from the external environment (either from the air or dissolved gases in seawater which in turn have equilibrated with the air) is generally not limiting, this suggests a fundamental molecular control on the macroscopic $\mathrm{CO}_{2}$ content in the air lying in the biochemistry of rubisco catalysis. If the external environment lies on the wrong side of the compensation barrier limit, net plant and algal growth ceases. If $\mathrm{CO}_{2}$ is too low, organisms cannot capture carbon. $\mathrm{O}_{2}$ and $\Gamma_{\mathrm{CO}_{2}}$ are interlinked, with linear co-variance (Tolbert et al., 1995, but see André 2011a, b also).

Tolbert et al. (1995) postulated an $\mathrm{O}_{2}$ compensation point $\Gamma_{\mathrm{CO}_{2}}$, defined as the upper limit of $\mathrm{O}_{2}$ at a given $\mathrm{CO}_{2}$ level, above which plants cannot have positive carbon uptake. On a planetary scale, this is the equilibrium point where $\mathrm{O}_{2}$ production to atmosphere by all green plants (including both higher plants and also microbial oxygenesis) equals the consumption by all living biosystems consuming $\mathrm{O}_{2}$ by dark respiration. The Tolbert et al. (1995) experimental data rather paradoxically implied the linkage of $\mathrm{\Gamma}_{\mathrm{CO}_{2}}$ to $\mathrm{O}_{2}$ was disconnected from the linkage of $\Gamma_{\mathrm{O}_{2}}$ to $\mathrm{CO}_{2}$. The experimental results of Tolbert et al. (1995) led Nisbet and Nisbet (2008) to propose the existence of a "prohibited region" in $\mathrm{O}_{2}: \mathrm{CO}_{2}$ space, where oxygen partial pressure would be so high that plant growth would stop, and eventually the plant would respire itself to death. However, André (2011a, b) re-investigated the high- $\mathrm{O}_{2}$ prohibited zone hypothesis, invalidating it by showing that the Tolbert et al. (1995) experiments, on which it was based, may have been affected by problems such as leakage artefacts.

Oxygen compensation $\Gamma_{\mathrm{O}_{2}}$ is related to rubisco specificity and $\mathrm{CO}_{2}$ concentration (C). André (2011a) demonstrated that a single reciprocal function exists linking $\Gamma_{\mathrm{CO}_{2}}$ and $\Gamma_{\mathrm{O}_{2}}$, and further showed that in large range of environmental parameters, the $\mathrm{CO}_{2}$ and $\mathrm{O}_{2}$ exchanges of the green (productive) part of plants can be fitted by a simple model that mimics the rubisco response to $\mathrm{O}_{2}$ and $\mathrm{CO}_{2}$ variations. The plant specificity factor ( $S p$ ) defined by André (2011a) takes into account both the specificity of the rubisco enzyme and also the $\mathrm{CO}_{2}$ gradient between the atmosphere and the rubisco site. Where $\mathrm{E}$ is the gross $\mathrm{O}_{2}$ evolution, a parameter linked to the electron transport rate generated by light in chloroplasts, and $\mathrm{R}$ is the rate of respiration, André (2011a) showed that a finite or realistic $\Gamma_{\mathrm{O}_{2}}$ (stated in \%; see Fig. 2) cannot be reached in a closed biosystem without a high rate of dark respiration $(R)$ :

$\Gamma_{\mathrm{O}_{2}}=\operatorname{Sp} C(E-R) /(0.5 E+R)$.

In a closed biosystem, André (2011a) showed that, dependent on plant specificity $S p$, crossing points of oxygenation and carboxylation gas exchanges exist between net photosynthesis and the opposite net photorespiratory processes, where

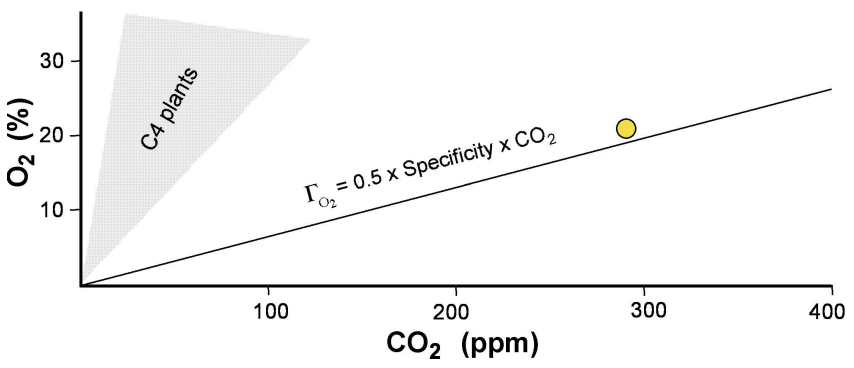

Fig. 2. Plot of $\Gamma_{\mathrm{O}_{2}}=0.5 \mathrm{Sp} \mathrm{C}$, assuming $\mathrm{Sp}$ of 0.132 , as for average C3 plants (André, 2011a), showing also the field of C4 plants (André, personal communication, 2011). Dot shows the approximate composition of the Earth's atmosphere before the industrial revolution, with about $290 \mathrm{ppm} \mathrm{CO}_{2}$ and nearly $21 \% \mathrm{O}_{2}$. Note also Supplement figure in the discussion of this work by Andre (2011c).

net photosynthetic uptake of $\mathrm{CO}_{2}$ equals gross $\mathrm{O}_{2}$ uptake. Taking $\mathrm{O}_{\mathrm{x}}$ as the oxygen concentration (in \%) at the crossing point, and $\mathrm{C}_{\mathrm{x}}$ as the $\mathrm{CO}_{2}$ concentration (in ppm), the crossing point (André 2011a, c) is expressed by reciprocal relationships:

$\mathrm{O}_{\mathrm{x}}=0.5 C S p$ and $\mathrm{C}_{\mathrm{x}}=2 \mathrm{O} / S p$.

Figure 2 shows this relationship. The crossing point is illustrated in the figure in the supplement to Andre (2011c).

Tolbert et al. (1995) noted that the atmospheric $\mathrm{CO}_{2}: \mathrm{O}_{2}$ ratio is very close to the balance determined by the plant specificity imposed by rubisco. They suggested that the "global atmospheric $0.03 \% \mathrm{CO}_{2}$ and $21 \% \mathrm{O}_{2}$ equilibria seem to be limits set by the average specificity properties of rubisco from plants and algae". For average C3 plants, with an average plant specificity $S p$ of $0.132 \% \mathrm{ppm}^{-1}$, André's (2011a) relationship gives $\mathrm{CO}_{2}$ of $317 \mathrm{ppm}$ for the modern atmospheric mixing ratio of dioxygen of $20.95 \% . \mathrm{CO}_{2}$ in the pre-industrial air had a mixing ratio of roughly $290 \mathrm{ppm}$.

This leads to the central hypothesis (Tolbert et al., 1995; Igamberdiev and Lea, 2006; Nisbet et al., 2007; Nisbet and Nisbet, 2008, André, 2011a) that rubisco controls the balance of $\mathrm{CO}_{2}$ and $\mathrm{O}_{2}$ in the air. Assuming a very simplified global system consisting only of $\mathrm{C} 3$ land plants (with a specificity of $0.132 \% \mathrm{O}_{2}$ per ppm $\mathrm{CO}_{2}$ ) and atmosphere (omitting oceans and the geological cycling of carbon dioxide in the oceanatmosphere system), the fit is remarkable. As André (2011a, and supplementary figure to 2011c) points out, "the $\mathrm{O}_{2}$ and $\mathrm{CO}_{2}$ concentrations of the pre-industrial atmosphere are the compensation points of the global biosystem".

But is this accidental, or has it evolved over time? Considering geologist James Hutton's tenet "the present is the key to the past", the specificity of rubisco may have helped sustain planetary habitability over geological time. Nisbet and Nisbet (2008) considered the greenhouse implications of this hypothesis. They suggested that, by setting the $\mathrm{O}_{2}: \mathrm{CO}_{2}$ ratio, the evolution of the enzymatic specificity of rubisco I, as 
it controlled plant specificity, may have controlled the planetary greenhouse ever since $3 \mathrm{Ga}$ ago, and hence also the maximum abundance of $\mathrm{CH}_{4}$ and water vapour in the air. André (2011a), suggested the $\mathrm{O}_{2}: \mathrm{CO}_{2}$ ratio is not merely fortuitous but is a consequence of a dynamic stabilisation of the atmosphere. More generally, André (2011a) strongly supported the hypothesis of co-evolutionary plant-atmosphere-climate feedbacks on the modern planet. Bernacchi et al. (2009) discuss the parabolic response to temperature variation of the net $\mathrm{CO}_{2}$ uptake rate in photosynthesis. The temperature optimum varies greatly, with species, ecotype, location and season. With all these variables, natural selection has much to act upon.

\section{The Greenhouse and its geological record}

Evolutionary competition, by natural selection of rubisco, has produced a mechanism that has the inherent ability to set the greenhouse warming of the air. If the atmospheric $\mathrm{O}_{2}: \mathrm{CO}_{2}$ ratio is biologically set, the obvious Darwinian hypothesis is that the planetary greenhouse, the Earth's surface temperature and the acidity of the oceans, have all been biologically set by natural selection over the aeons (Nisbet, 2002; Nisbet and Nisbet, 2008). But did rubisco specificity co-evolve with the global greenhouse? Can natural selection sustain an equable global temperature? Or is the clemency of the planetary climate over the aeons simply an inorganic geochemical consequence of the nature of weathering $/ \mathrm{CO}_{2}$ feedbacks on the planetary surface, as argued convincingly by Walker et al., (1981)?

Planetary surface temperature is governed by $\mathrm{CO}_{2}$, supplemented by $\mathrm{CH}_{4}$ and minor gases, and indirectly by $\mathrm{N}_{2}$ and $\mathrm{O}_{2}$ pressure. The dominant greenhouse gas is water vapour in the air. This can be thought of as a "responding" feedback to variations in gases such as $\mathrm{CO}_{2}, \mathrm{CH}_{4}$ and $\mathrm{N}_{2} \mathrm{O}$, rather than a "controlling" gas. The modern atmosphere is globally mixed over a period of a year, and equilibrates quickly with the ocean surface and upper waters, a process speeded by planktonic use of carbonic anhydrase to draw down $\mathrm{CO}_{2}$ across the air/ocean interface, and by physical mixing on wave crests that are themselves dependent on climate-driven wind.

Stability in the ocean/atmosphere system is conferred by the very large (and long-lived) biologically-created reservoirs of atmospheric $\mathrm{N}_{2}$ and $\mathrm{O}_{2}$, and reciprocally by the burial of reduced organic matter, which is recycled via volcanoes by plate tectonics. In the oxygen-rich atmosphere created by photosynthesis, any emitted $\mathrm{CH}_{4}$ and $\mathrm{CO}$ molecules are within a few years converted to $\mathrm{CO}_{2}$. Rates of biological processes vary exponentially with temperature. This means that, compared to geological timescales, biological feedback controls can in principle act rapidly, controlling $\mathrm{CO}_{2}$ and $\mathrm{CH}_{4}$, and thereby managing the temperature of the ocean/atmosphere system.
Inorganic processes have a longer time-scale. Atmospheric $\mathrm{CO}_{2}$, through acid rain, influences the rate of chemical erosion and the supply of alkalinity by rivers to seawater. By equilibrating with ocean water, atmospheric $\mathrm{CO}_{2}$ helps to set ocean $\mathrm{pH}$. This in turn influences carbonate precipitation and thus the inorganic feedback controls on $\mathrm{CO}_{2}$ (Walker et al., 1981; see also Fig. 8.2 in Kasting, 2008). Carbonate precipitation, and hence $\mathrm{CO}_{2}$ in the air, also depends on the alkalinity of the ocean, set by the combined effects of river runoff (which is itself influenced by atmospheric $\mathrm{CO}_{2}$ ) and mid-ocean ridge hydrothermal processes (which are less linked to the atmosphere but do depend on the $\mathrm{CO}_{2}$ content of the seawater).

As the Earth has evolved, the continental area may have changed over time (but see discussion in Arndt and Nisbet, 2012). Moreover, as the potential temperature of the mantle has cooled, thickening lithosphere may have became more capable of supporting mountains and hence more erosion of silicates taking up $\mathrm{CO}_{2}$. Thus, there may be purely inorganic feedbacks capable of changing and managing the greenhouse over time as the external inputs varied. Zeebe and Caldeira (2008) demonstrated a close mass balance of carbon cycle fluxes in the late Pleistocene, which they interpreted as evidence for control by the weathering feedback.

\section{Long-term controls on the planetary atmosphere and temperature}

Over time, the Sun has steadily warmed (Gough et al., 1981) with significant consequences for life on Earth (Sagan and Chyba, 1997; Goldblatt et al., 2009; Nisbet and Nisbet, 2008; Ueno et al., 2009; Rosing et al., 2010; see also Fig. 8.1 in Kasting, 2008). It might be expected that, under the faint young Sun, the Hadean and Archaean Earth would have been covered in ice (see Nisbet and Sleep, 2001; Nisbet and Fowler, 2004). If the oceans are cool now, in a modern world subject to repeated ice ages, then billions of years ago under a faint Sun, the planet ought to have existed in deep permafrost, too cold for life except near volcanic vents.

However, the evidence in Jack Hills zircons in Western Australia that implies the presence of liquid water oceans $4.3 \mathrm{Ga}$ ago (Wilde et al., 2001), and the presence of sedimentary rocks in the $3.8 \mathrm{Ga}$ old Isua belt (Rosing, 1999), both imply that surface temperatures permitted liquid water. High concentrations of atmospheric greenhouse gases, either $\mathrm{CO}_{2}$ or perhaps methane, could have prevented the oceans from freezing over.

From the presence of magnetite and the absence of siderite in Archaean sediments, Rosing et al. (2010) infer that $\mathrm{CO}_{2}$ levels in the mid to late Archean atmosphere were little greater than those of today. Nevertheless, in the midArchaean, around 3.2 Ga ago, Hessler at al. (2004) showed that the minimum partial pressure of carbon dioxide was several times higher than present-day values. Grotzinger and 
Kasting (1993) showed that even at $\mathrm{CO}_{2}$ partial pressures of 0.1 bar, the $\mathrm{pH}$ of the Archaean ocean need not have been much different from the modern value around 8.1.

It appears that the planetary thermostat has been adjusted down as the Sun has warmed up. A wholly inorganic control is plausible (Holland, 1984), initially with high atmospheric $\mathrm{CO}_{2}$ in the early Precambrian, and then with lower $\mathrm{CO}_{2}$ as the Earth aged and the Sun warmed, while the continental crust evolved, the lithosphere thickened and mountains grew taller. The anthropic principle is relevant here: we may live on a planet whose inbuilt inorganic geochemical evolution, via changes in the composition and area of the surface, the erodibility of continental crust, coupled with the cooling of the mantle, has over the aeons matched the warming of the Sun with a declining atmospheric greenhouse. Is the longterm maintenance of life-sustaining conditions on Earth an anthropic accident of chemistry, pre-destined when this particular planet accreted, with the evolving biosphere a passive occupant of the inorganic aging of the planetary environment?

Or can the physical environment itself be malleable, moulded by evolution, so that the physical setting itself is reshaped as the biosphere evolves? Can biology, by its command of kinetics, overrule the long-term equilibria of geological supplies and sinks between the Earth's interior and surface? Can rapid biological processes, with their large carbon fluxes, overwhelm the smaller fluxes of the slower inorganic controls? By sequestering reservoirs such as atmospheric oxygen and buried sedimentary carbon, and by setting parameters such as temperature and $p \mathrm{H}$, can biological processes control the kinetics of inorganic chemistry, and set conditions of the state under which thermodynamic equilibria operate on a planetary scale?

There is strong controversy over the temperature of the oceans in the mid-Archaean. From isotopic evidence in cherts, Knauth and Lowe (2003), and Robert and Chaussidon (2006) suggested temperatures up to $50-70^{\circ} \mathrm{C}$. A methane greenhouse would be the obvious explanation if temperatures really were so high. Almost all atmospheric methane is a biological product, and there is good evidence for mid-Archean methanogenesis (e.g. Grassineau et al., 2006), so a methanerich atmosphere is indeed possible. If so, the biological cycle of methanogenesis, balanced by methanotrophy, atmospheric and sedimentary oxidation (including anaerobic oxidation) sustained, and thus controlled the mid-Archaean global surface temperature. But did biological control continue?

\section{Feedbacks in rubisco evolution}

About $2.9 \mathrm{Ga}$ ago, large scale sedimentary calcite and dolomite deposits appeared, deposited in shallow water (Nisbet et al., 2007). Moreover since then, except in a few notable but isolated time periods, the $\mathrm{C}$ isotope ratio in sedimentary carbonates has been broadly modern in aspect
(Schidlowski, 1988). The implication is that the controls on carbon partition between organic matter and carbonate deposition into sediment, whether inorganic or biologically precipitated, have been broadly unchanged from $2.9 \mathrm{Ga}$ ago to now.

Photosynthesis is today the key biological control on $\mathrm{CO}_{2}$ (Hahn, 1987), and also indirectly controls $\mathrm{CH}_{4}$ production from dead organic matter. $\mathrm{CO}_{2}$ uptake is primarily by plants on land and in the ocean. $\mathrm{CO}_{2}$ release is primarily by respiration, supplemented by processes such as biomass burning and conversion of biologically-generated methane. Consider a bathtub: the water level depends on the position of the exit - even a flux as small as a dripping tap can fill the tub if the plug is in. Similarly, the present global temperature (set by the $\mathrm{CO}_{2}$ and $\mathrm{CH}_{4}$ greenhouse) must be determined by the primary exit control on the atmospheric $\mathrm{CO}_{2}$ burden, which is rubisco's specificity (Tcherkez et al., 2006; Gutteridge and Pierce, 2006). If rubisco were more effective at drawing down $\mathrm{CO}_{2}$ from the air (e.g. with a take-over of the biosphere by $\mathrm{C} 4$ plants, so that the overall average plant specificity changed markedly), eventually sequestering organic carbon in peats and sediments, the planet would cool. If rubisco were less effective and $\mathrm{CO}_{2}$ rose, the planet would warm, and oceans would become more acidic and deoxygenated.

Rubisco is a biological product and like all biology is subject to natural selection. As the environment changes, evolution will act on rubisco. It is thus a tenable hypothesis that, at least in part, after an initial lucky accident that allowed clement early conditions to host the origin of life (Sleep et al., 2001), the following broad stability of planetary temperature over the aeons occurred because natural selection of competing rubisco molecules favoured those biological processes that, by managing the atmosphere, maximised the likelihood of the survival of microbial consortia. Should a large $\mathrm{CO}_{2}$-influencing geological event occur (such as a massive plume eruption over a few hundred thousand to a few million years), natural selection will certainly induce an evolutionary response in rubisco specificity.

Events happen, but it is our argument that this in the broadest terms is an evolutionarily stable system, in which rubisco fitness will evolve to maximise biological survival: in other words, to sustain the equable (i.e. maximum productivity) climate. In our interpretation the $\mathrm{CO}_{2}, \mathrm{O}_{2}$ and indeed $\mathrm{N}_{2}$ burdens of the atmosphere are not independent of each other, but, to the contrary, all three co-evolve together, as managed by the biosphere.

Consider the plankton, both eukaryotic and prokaryotic. Intrinsically, only a few species would be expected, equal in number to the number of bio-limiting resources $-\mathrm{N}, \mathrm{P}, \mathrm{Fe}, \mathrm{Si}$, inorganic carbon, light energy, trace metals. Yet thousands of plankton species coexist in natural waters. This paradox is resolved by the hypothesis (Huisman and Weissing, 1999) that resource competition creates oscillating and chaotic populations. These oscillations allow many species to coexist, although depending on only a few discrete resource types. 
Natural selection, presumably including selection for rubisco specificity in photosynthesisers, operates on the oscillating populations, to select for survivability.

Separately, there is evidence that large variations in key indicators such as the N:P ratio occur in the various microbial "biomes" in the ocean. While the bulk global ocean N:P ratio (16:1) is very highly conserved on a planet-wide basis, the local N:P can vary widely, from 11:1 to 20:1 (Weber and Deutsch, 2010). In the global ocean, reservoirs of $\mathrm{N}$ and $\mathrm{P}$ may be kept near the Redfield ratio (C:N:P = 106:16:1, the stoichiometric molecular ratio of carbon, nitrogen and phosphorus in oceanic plankton), by competition between species that add $\mathrm{N}$ to the ocean through biological $\mathrm{N}_{2}$ fixation when $\mathrm{N}$ is limiting, but when it is not limiting are out-competed by other plankton (Weber and Deutsch, 2010). Collectively in the global ocean circulation, the biomes manage a very efficient global regulation of $\mathrm{N}: \mathrm{P}$, yet individual biomes can be very different, each selected to be best adapted for local conditions. If this is so for microbial $\mathrm{N}$ and $\mathrm{P}$, could a similar evolutionary mechanism control $\mathrm{CO}_{2}$ ?

In the ocean, microbial biomes based on photosynthetic plankton have climate impact. Selection over time will favour biomes that are best fitted to survive by producing favourable responses from the environment, even if those benefits are only marginal. Over millions of years, selection would favour phytoplankton species which contained rubisco with specificities that at each "present" moment maximised climate favourability. Ecological consortia that act adversely to climate will be selected against. In extreme cases, global over-heating or rare catastrophic glaciations would eliminate organisms whose blooms destabilised global climate. Over time, by maximising survival, repeated selective co-evolutionary feedbacks would fine-tune microbial rubisco specificities as the rubiscos in turn controlled the greenhouse impact of the atmosphere.

On land, similar selective pressures could apply. Rainforests substantially manage local and regional climates, controlling albedo via leaf colour and also by trapping and transpiring water and emitting aerosols to nucleate cloud cover. On a large scale, major forest biomes strongly influence global weather, for instance by influencing the location of major convergence zones and the jet streams. Similarly, in the boreal and tropical forests, carbon sequestration by peat bogs has global impact by drawing down $\mathrm{CO}_{2}$, a long-term global cooling impact that is countered in the short-term by methane emission. In Siberia, for example, an astonishing $70 \mathrm{Pg}$ of carbon have accumulated since the early Holocene (Smith et al, 2004), roughly a quarter of all carbon accumulated since the Last Glacial Maximum.

In the relatively recent geological past, $\mathrm{C} 4$ plants have evolved (Sage, 2004). These plants, which through convergent evolution have appeared in many plant groups, preconcentrate $\mathrm{CO}_{2}$ around the rubisco, and thus can thrive at lower levels of ambient $\mathrm{CO}_{2}$ than $\mathrm{C} 3$ plants. Andre (2011a, b) points out that with sluggish rubisco, they have high plant specificity and little photorespiration. Thus, $\mathrm{C} 4$ plants are adapted to survive in the warm tropics when global $\mathrm{CO}_{2}$ is low. In the $\mathrm{C} 3 / \mathrm{C} 4$ competition, areas under $\mathrm{C} 4$ plants expand in glacial times, while $\mathrm{C} 3$ plants prosper in interglacial episodes when $\mathrm{CO}_{2}$ is higher. Globally, $\mathrm{C} 4$ plants flourish in the tropics at times of ice ages, when atmospheric $\mathrm{CO}_{2}$ may be below $200 \mathrm{ppm}$. In these circumstances, the $\mathrm{C} 4$ preconcentration process clearly gives them advantage over $\mathrm{C} 3$ plants. Contrarily, higher $\mathrm{CO}_{2}$ in inter-glacial periods gives advantage to $\mathrm{C} 3$ plants (André, 2011b). We refer specifically to the diagram by Andre (note especially the supplementary Fig., 2011c). Interestingly, C4 plants (especially grasses) often form fire ecologies: though fires immediately return $\mathrm{C}$ to the air, their long-term impact is to remove $\mathrm{C}$ by sequestering it as charcoal, which is stable over millions of years. The pre-industrial global $\mathrm{CO}_{2}$ level may have been set (Andre $2010 \mathrm{~b}$ ) at $\sim 300 \mathrm{ppm} \mathrm{CO} \mathrm{CO}_{2}$ and $\sim 21 \% \mathrm{O}$, by competition between the dominant $\mathrm{C} 3$ plants (favoured under high $\mathrm{CO}_{2}$ ) and the specialist $\mathrm{C} 4$ plants (favoured under lower $\mathrm{CO}_{2}$ values and higher $\mathrm{O}_{2}$ ).

More generally, in the oxygen-rich atmosphere, on a warm planet at a time of increased atmospheric $\mathrm{CO}_{2}$ (say from a volcanic injection), carbon fixation by photosynthesis will increase. In these circumstances, with $\mathrm{CO}_{2}$ abundantly accessible, it is possible that natural selection will favour photosynthetic organisms that use a catalytically faster variant of rubisco. Eventually photosynthesis will use up the excess $\mathrm{CO}_{2}$, reducing greenhouse warming by drawing down $\mathrm{CO}_{2}$ towards $\Gamma_{\mathrm{CO}_{2}}$. In the cooler low- $\mathrm{CO}_{2}$ environment that results, there will be a greater requirement for rubisco variants that have greater specificity for $\mathrm{CO}_{2}$ over $\mathrm{O}_{2}$ (Tcherkez et al., 2006), but this adaptation means draw-down rates will be reduced. Eventually, as organic matter is recycled, the ratio of $\mathrm{CO}_{2}: \mathrm{O}_{2}$ will rebalance temperature again. The very large $\mathrm{O}_{2}$ reservoir, which changes only slowly as it is much larger than the annual flux, serves as a stabiliser on the system, its "memory", drawing $\mathrm{CO}_{2}$ back to long-term average levels.

Over geological time there have been essentially three states of the atmosphere/ocean system (Arndt and Nisbet, 2012):

(1) The early-mid Archaean anoxic ocean/atmosphere, prior to the evolution of rubisco I (about from the beginnings of life until about $2.9 \mathrm{Ga}$ ago), which was processed by anoxic photosynthesisers (rubisco II), and also rubisco III methanogens;

(2) In the late Archaean and earliest Proterozoic, an episode of perhaps $500 \mathrm{Ma}$ after the evolution of rubisco I, from about $2.9 \mathrm{Ga}$ ago until roughly 2.4 to $2.3 \mathrm{Ga}$ ago (Nisbet et al., 2007), when the ocean and atmosphere were broadly anoxic but widespread oxygen "oases" existed in the photic zone of the uppermost ocean and in coastal lagoons;

(3) From about 2.3 to $2.4 \mathrm{Ga}$ ago until the pre-industrial "present", the current system with oxic air and oxygenated ocean, sustained by oxygenic (rubisco I) photosynthesis. 
Our hypothesis is confined to rubisco I specificity. We have argued that rubisco I did not evolve until about $2.9 \mathrm{Ga}$ ago (Nisbet et al., 2007). Prior to this, the controls we suggest in our hypothesis would have been absent. However, both methanogenesis and anoxygenic photosynthesis were active before $2.9 \mathrm{Ga}$, and the rubisco family may have originated as a rubisco III-like form, in a strictly anaerobic methanogen. It is not improbable that natural selection may have acted to balance the $\mathrm{CH}_{4}$ greenhouse created by rubisco-III methanogens during the long period from the origin of methanogens to the late Archaean.

Figure 3, modelled on industrial PID (proportionalintegral-derivative) controllers, illustrates the way natural selection, acting on rubisco specificity, may have managed the surface temperature, at least in the past $\sim 2.3 \mathrm{Ga}$ since the air became oxygen-rich. The "optimum" temperature is the temperature at which the contemporaneous (at that "present") global biosphere has maximum productivity. If an external perturbation occurs, such as a volcanic eruption or solar warming, then there will be a proportional response as photosynthesis and respiration increase/decrease or decrease/increase, taking up or releasing $\mathrm{CO}_{2}$. Methane too will change, especially as temperature change affects water precipitation in rain and snow.

Secondly, there will also be an integrated response, as carbon is sequestered or, conversely, released, for example by precipitation or dissolution of calcite, or by the deposition or release of organic matter, for example in sea bed organic deposits, or in peat bogs or fires. Biological C sequestration can be rapid. For example the immense peat deposits of NW Siberia and the Hudson Bay lowlands have accumulated remarkably quickly, beginning less than $10 \mathrm{ka}$ ago (Smith et al., 2004). Likewise, tropical peat formation in Amazonia and the Congo accelerated then, and the accumulation of $\mathrm{C}$ in the Black Sea floor. Thus, the global change in primary production after Termination 1B (at the start of the Holocene) did indeed cause an immediate change in $\mathrm{C}$ burial rate. Sequestration is not necessarily linked to nutrients as Fe, $\mathrm{P}$ etc. are recycled: many coals are very pure $\mathrm{C}$ with little residual $\mathrm{Fe}$. Moreover, there will be a strong integrated response from methane recycling organic matter.

Thirdly, in addition to this, there will be a derivative response, as organisms are favoured or selected against, according to their balance between rubisco specificity and the rate of catalytic turnover and productivity. Over the longer term via this natural selection for specificity, especially if the external perturbation is prolonged (e.g. solar warming), the control will be adaptive, iteratively ramping up so that evolution will change the contemporaneous optimum temperature at which the biosphere has maximum productivity. For example, in future as the aging Sun brightens, dynamically adaptive evolution will favour $\mathrm{C} 4$ plants (capable of thriving in low- $\mathrm{CO}_{2}$ air) over $\mathrm{C} 3$ plants. This will stabilise global temperature by reducing the atmospheric greenhouse as the solar input increases.
Thus, there is circumstantial but permissive evidence to support the hypothesis that rubisco manages the atmosphere and has done so for the past 2.3 billion years or more. We do not deny the validity of the inorganic equilibria - indeed, our hypothesis depends on them - but as a consequence of the environmental conditions of thermodynamic state that are sustained by the driving selection of $\mathrm{CO}_{2}$ over $\mathrm{O}_{2}$ controlled by rubisco specificity. Once that is set, then the oceanic $\mathrm{pH}$ and temperature follow, and perhaps atmospheric pressure also; from them, the inorganic equilibria are determined. Moreover, in an evolutionarily stable system there is no need for constant $\mathrm{CO}_{2}: \mathrm{O}_{2}$ - indeed, the glacial/interglacial changes at the start of the Holocene shows that this ratio can change by up to $40 \%$ within a millennium. In episodes of rapid albedo or solar change, the large and thus slow-changing $\mathrm{O}_{2}$ reservoir acts as "memory" to constrain specificity fluctuations, helping the global average plant specificity to maximise survival, given albedo and insolation. The even larger $\mathrm{N}_{2}$ burden may act similarly on the nitrogen cycle.

\section{Testable implications of the hypothesis of co-evolution between rubisco and climate}

This hypothesis implies testable propositions:

(1) That inorganic controls on carbonate precipitation are not the primary controls on atmospheric $\mathrm{CO}_{2}$ and $\mathrm{O}_{2}$, but rather that atmospheric abundances of $\mathrm{CO}_{2}, \mathrm{O}_{2}$ and $\mathrm{CH}_{4}$ are primarily set by biological control. This biological control determines the wider environment (pressure, temperature, acidity, redox) in which inorganic reactions occur. The proposition predicts that atmospheric mixing ratios of $\mathrm{CO}_{2}, \mathrm{O}_{2}$ and $\mathrm{CH}_{4}$, and their variability, are fully explicable by biological processes.

(2) That, in addition to management of carbon dioxide, biological sequestration of nitrogen into the atmosphere (which creates atmospheric air pressure) has overwhelmed the inorganic (geological) processes that otherwise would be in control. This predicts that nitrogenase, often thought of as inefficient, must be as well tuned to its task as rubisco I. Planctomycetes are ancient and it is likely they have also played an important role over time, producing $\mathrm{N}_{2}$ by reacting $\mathrm{NH}_{4}^{+}$ with $\mathrm{NO}_{3}^{-}$. However, note that Kasting (1993) has argued that $\mathrm{N}_{2}$ would be a dominant component of the atmosphere even in the absence of life.

(3) That for any planet, chance trajectories of surface temperature which sustain clement conditions over geological aeons by purely inorganic processes are improbable, given the complex parameters of solar brightening, geological partitioning of $\mathrm{C}, \mathrm{O}, \mathrm{N}$ and $\mathrm{S}$ species between the planetary interior and the surface, exchange between ocean and air - and time. In the Earth's early history, inorganic processes may have produced clement conditions for a relatively brief period $\left(10^{5}-\right.$ $10^{7}$ years) (Sleep et al., 2001), but this could not have been sustained over aeons. The implication is that it will be very 


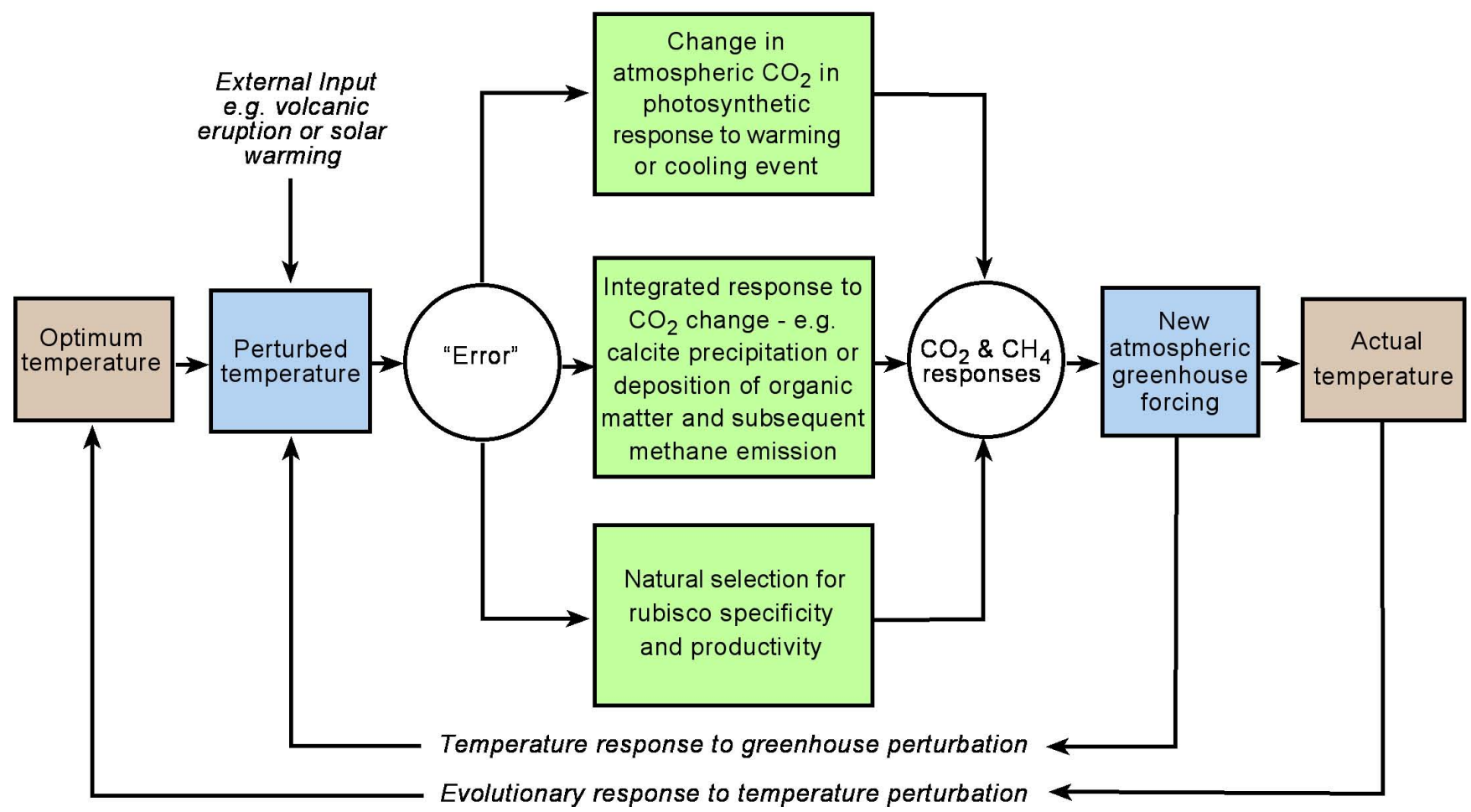

Fig. 3. Possible controls on temperature of the ocean/atmosphere system, modelled on a PID controller, illustrating the way natural selection, acting on rubisco specificity, can manage the surface temperature.

difficult to create an inorganic feedback model that, alone, successfully sustains clement temperatures over the aeons. In contrast, the continually selective nature of biological evolution has inbuilt adaptation. What we propose thus is the hypothesis of co-evolution of life and its geochemical setting. To return to our opening statement, the past is the sum of the present moments: at each present moment the temperature and $\mathrm{pH}$ are set by life's control on the greenhouse, and it is in this setting that inorganic "Urey" control operates.

Perhaps only biological processes (Lovelock and Whitfield, 1982), driven by natural selection, could have allowed Earth to remain clement, with surface temperatures following a very improbable trajectory through time. The "Daisyworld" parable of Watson and Lovelock (1983) illustrates the potential of biological control. By mutually tuning rubisco and the geochemical environment to each other, the action of natural selection, on the kinetics of carbon acquisition by the plants of the planetary estate, may have directed the temperature, ocean $\mathrm{pH}$ and wider geochemical setting in which equilibrium geochemical buffers have acted and new life forms have evolved. Gutteridge and Pierce (2006) cite the allusion by Dr. Pangloss to the Great Chain of Being: "There is a concatenation of events in the best of possible worlds". Pangloss may be right. Given our present intervention to change atmospheric $\mathrm{CO}_{2}$ and oceanic $\mathrm{pH}$, and to deoxygenate the oceans, it is also worth considering Candide's reply, "let us cultivate our garden".
Acknowledgements. Many thanks to Marcel André for his kind and very helpful corrective comments, and also our grateful thanks to Jan Zalasiewicz, Lee Kump, Jim Kasting, David Schwartzman, Tyler Volk, for comments, generous, thoughtful, and helpful, even when in profound disagreement, and to Darren Gröcke for editorial insight.

Edited by: D. R. Gröcke

\section{References}

André, M. J.: Modelling ${ }^{18} \mathrm{O}_{2}$ and ${ }^{16} \mathrm{O}_{2}$ unidirectional fluxes in plants: I. Regulation of pre-industrial atmosphere, Biosystems, 103, 239-251, 2011a.

André, M. J.: Modelling ${ }^{18} \mathrm{O}_{2}$ and ${ }^{16} \mathrm{O}_{2}$ unidirectional fluxes in plants: II. Analysis of Rubisco evolution, Biosystems, 103, 252264, 2011b.

André, M. J.: Interactive comment on "The regulation of the air: a hypothesis" by e.g. Nisbet et al., Solid Earth Discuss., 3, C474C476. 2011c.

Arndt, N. T. and Nisbet, E. G.: Processes on the young Earth and the habitats of early life, Annu. Rev. Earth Planet. Sci., 40, 521-49. 2012.

Badger, M. R., Price, G. D., Long, B. M., and Woodger, F. J. The environmental plasticity and ecological genomics of the cyanobacterial $\mathrm{CO}_{2}$ concentrating mechanism, J. Exp. Bot., 57, 249-265. 2006. 
Bernacchi, C. J., Rosenthal, D. M., Pimental, C., Long, S. P., and Farquhar, G. D.: Modeling the temperature dependence of C3 photosynthesis. 2010. Chapter 10, in: Photosynthesis in silico: Understanding Complexity from Molecules to Ecosystems, edited by: Laisk, A., Nedbal, L., and Govindjee, Springer Science and Business Media B.V., 231-246. 2009.

Berry, J. A., Collatz, G. J., Guy, R. D., and Fogel, M. D.: The compensation point: can a physiological concept be applied to global cycles of carbon and oxygen? in: Regulation of Atmospheric $\mathrm{CO}_{2}$ and $\mathrm{O}_{2}$ by Photosynthetic Carbon Metabolism, Oxford Univ. Press, New York, 234-238, 1994.

Falkowski, P.: Evolution of the nitrogen cycle and its influence on the biological sequestration of $\mathrm{CO}_{2}$ in the ocean, Nature, 387, 272-275, 1997.

Farquhar, G. D., von Caemmerer, S., and Berry, J. A.: A biochemical model of photosynthetic $\mathrm{CO}_{2}$ assimilation in leaves of $\mathrm{C} 3$ species, Planta, 149, 78-90, 1980.

Goldblatt, C., Matthews, A. J., Claire, M., Lenton, T. M., Watson, A. J., and Zahnle, K. J.: There was probably more nitrogen in the Archean atmosphere - this would have helped resolve the Faint Young Sun paradox, Geochim. Cosmochim. Ac., 73, Supp. 1 A446, 2009.

Gough, D. O.: Solar interior structure and luminosity variations, Solar Physics, 74, 21-34, 1981.

Grassineau, N. V., Abell, P., Appel, P. W. U., Lowry, D., and Nisbet, E. G.: Early life signatures in sulphur and carbon isotopes from Isua, Barberton, Wabigoon (Steep Rock) and Belingwe greenstone belts (3.8 to $2.7 \mathrm{Ga}$ ), in: Evolution of Early Earth's Atmosphere, Hydrosphere and Biosphere - Constraints from Ore Deposits, edited by: Kesler, S. E. and Ohmoto, H., Geol. Soc. Am., Special Publication, 198, 33-52, 2006.

Grotzinger, J. P. and Kasting, J. F.: New constraints on Precambrian ocean chemistry, J. Geol., 101, 235-243, 1993.

Gutteridge, S. and Pierce, J.: A unified theory for the basis of the limitations of the primary reaction of photosynthetic $\mathrm{CO}_{2}$ fixation: was Dr. Pangloss right? Proc. Natl. Acad. Sci., 103, 72037204, 2006.

Hahn, B. D.: A mathematical model of photorespiration and photosynthesis, Ann. Bot.-London, 60, 157-169, 1987.

Hessler, A. M., Lowe, D. R., Jones, R. L., and Bird, D. K.: A lower limit for atmospheric carbon dioxide levels 3.2 billion years ago, Nature, 428, 736-738, 2004.

Holland, H. D.: The chemical evolution of the atmospheres and oceans, Princeton: Princeton University Press, 582 pp., 1984.

Huisman, J. and Weissing, F. J.: Biodiversity of plankton by species oscillation and chaos, Nature, 402, 407-410, 1999.

Igamberdiev, A. U. and Le, P. J.: Land plants equilibrate $\mathrm{O}_{2}$ and $\mathrm{CO}_{2}$ concentrations in the atmosphere, Photosynth. Res., 87, 177-194, 2006.

Kasting, J. F.: The Primitive Earth, Chapter 8 in Prebiotic evolution and astrobiology, edited by: Wong, J. T.-F. and Lazcano, A., Landes Bioscience, Austin, Texas, USA, 2008.

Kasting, J. F. and Walker, J. C. G.: Limits on oxygen concentration in the prebiological atmosphere and the rate of abiotic fixation of nitrogen, J. Geophys. Res., 86, 1147-1158, 1981.

Kasting, J. F., Whitmire, D. P., and Reynolds, R. T.: Habitable zones around main sequence stars, Icarus, 101, 108-128, 1993.

Knauth L. P. and Lowe D. R.: High Archean climatic temperature inferred from oxygen isotope geochemistry of cherts in the 3.5
Ga Swaziland Supergroup, South Africa, Geol. Soc. Am. Bull., 115, 566-80, 2003.

Keeling, R. F. and Shertz, S. R.: Seasonal and interannual variations in atmospheric oxygen and implications for the global carbon cycle, Nature, 358, 723-727, 1992.

Lovelock, J. E. and Whitfield, M.: Life span of the biosphere, Nature, 296, 561-563, 1982.

Nisbet, E. G.: Fermor lecture: The influence of life on the face of the earth: garnets and moving continents, in: The early Earth: physical, chemical and biological development, edited by: Fowler, C. M. R., Ebinger, C. J., and Hawkesworth, C. J., Geol. Soc. London Special Publication, 199, 275-307, 2002.

Nisbet, E. G. and Sleep, N. H.: The habitat and nature of early life, Nature, 409, 1083-1091, 2001.

Nisbet, E. G. and Fowler, C. M. R.: The early history of life, Volume 8 Biogeochemistry, Ed. Schlesinger, W. H., in: Treatise on Geochemistry, edited by: Holland, H. D. and Turekian, K. K. Academic Press, Chapter 8.01, 1-41, 2004.

Nisbet, E. G. and Nisbet, R. E. R.: Methane, oxygen, photosynthesis, rubisco and the regulation of the air through time, Philos. T. R. Soc. Lon. B, 363, 2745-2754, 2008.

Nisbet, E. G., Grassineau, N. V., Howe, C. J., Abell, P. I., Regelous, M., and Nisbet, R. E. R.: The age of Rubisco: the evolution of oxygenic photosynthesis, Geobiology, 5, 311-335, 2007.

Robert, F. and Chaussidon, M.: A palaeotemperature curve for the Precambrian oceans based on silicon isotopes in cherts, Nature, 443, 969-972, 2006.

Rosing, M.: 13C-depleted carbon in >3700 Ma seafloor sedimentary rocks from West Greenland, Science, 283, 674-676, 1999.

Rosing, M. T., Bird, D. K., Sleep, N. H., and Bjerrum, C. J.: No climate paradox under the faint early Sun, Nature, 464, 744-749, 2010.

Sagan, C. and Chyba, C.: The early faint sun paradox: organic shielding of ultraviolet-labile greenhouse gases, Science, 276, 1217-1221, 1997.

Sage, R. F.:The evolution of C4 photosynthesis, New Phytologist, 161, 341-370, 2004.

Schidlowski, M.: A 3800 million year record of life from carbon in sedimentary rocks, Nature, 333, 313-318, 1988.

Sleep, N. H., Zahnle, K., and Neuhoff, P. S.: Initiation of clement surface conditions on the earliest Earth, P. Natl. Acad. Sci. USA, 98, 3666-3672, 2001.

Smith, L. C., Macdonald, G. M., Velichko, A. A., Beilman, D. W., Borisova, O. K., Frey, K. E., Kremenetski, K. V., and Sheng, Y.: Siberian peatlands a net carbon sink and global methane source since the early Holocene, Science, 303, 353-356, 2004.

Tcherkez, G. G. B., Farquhar, G. D., and Andrews, T. J.: Despite slow catalysis and confused substrate specificity, all ribulose bisphospahte carboxylases may be nearly perfectly optimized, Proc. Natl. Acad. Sci., 103, 7246, 2006.

Tolbert, N. E., Benker, C., and Beck, E.: The oxygen and carbon dioxide Compensation points of $\mathrm{C}_{3}$ plants: possible role in regulating atmospheric oxygen, Proc. Natl. Acad. Sci., 92, 11230 11233, 1995.

Ueno, Y., Johnson, M. S., Danielache, S. O., Eskebjerg, C., Pandey, A., and Yoshida, N.: Geological sulfur isotopes indicate elevated OCS in the Archean atmosphere, solving faint young sun paradox, Proc. Natl. Acad. Sci., 106, 14784-14789, 2009.

Walker, J. C. G., Hays, P. B., and Kasting, J. F.: A negative feed- 
back mechanism for the long-term stabilization of Earth's surface temperature, J. Geophys. Res., 86, 9776-9782, 1981.

Watson, A. J. and Lovelock, J. E.: Biological homeostasis of the global environment: the parable of Daisyworld, Tellus 35B, 284289. 1983.

Weber, T. S. and Deutsch, C.: Ocean nutrient ratios governed by plankton biogeography, Nature, 467, 550-554, 2010.
Wilde, S. A., Valley, J. W., Peck, W. H., and Graham, C. M.: Evidence from detrital zircons for the existence of continental crust and oceans on the Earth 4.4 Gyr ago, Nature, 409, 175-178, 2001.

Zeebe, R. E. and Caldeira, K.: Close mass balance of long-term carbon fluxes from ice-core $\mathrm{CO}_{2}$ and ocean chemistry records, Nature Geoscience 1, 312-316. 2008. 